\title{
Evaluation of remotely sensed evapotranspiration products in a large scale Australian arid region: Cooper Creek, Queensland
}

\author{
$\underline{\text { A. Mohammadi }}^{\text {a }}$, J.F. Costelloe ${ }^{\text {a }}$ and D. Ryu ${ }^{\text {a }}$ \\ ${ }^{a}$ Department of Infrastructure Engineering, University of Melbourne \\ Email: abbasm@student.unimelb.edu.au
}

\begin{abstract}
Accurate estimation of evapotranspiration (ET), as the second largest term of the water budget after precipitation, is necessary for arid zone catchments, where conservation of limited water resources is vital for the natural environment and human lives but where reliable ground measurements are sparse due to low population densities. Emergence of remotely sensed products has given promising results in better quantification of spatial and temporal behaviour of evapotranspiration, but these products are mainly calibrated in more humid zones with almost stable land cover, and the emphasis is on transpiration as the main term of water loss. Therefore, utilization of remotely sensed ET products requires further evaluation in arid regions. MOD16 and CMRSET are two of the most well-known actual ET (AET) datasets available for Australia, provided by NASA and CSIRO respectively. In order to validate the accuracy of these products, a $480 \mathrm{~km}$ reach of Cooper Creek in the Lake Eyre Basin (LEB), with an area of 22,000 km², was chosen. Transmission losses (TL) in this large-scale, low gradient floodplain were estimated by considering rainfall, gauged (inflow and outflow) and ungauged streamflow volumes for 14 flood events between 2000 and 2012. It was assumed that satellite AET retrieved during and post-flooding should approximate to the transmission loss estimated for individual flood events. Results indicate that CMRSET AET performs well in large events $(\mathrm{TL}>9500 \mathrm{GL})$ with less than $8 \%$ absolute error, but its performance decreases for medium sized floods $(\mathrm{TL}=$ $4000-8000 \mathrm{GL}$ ), with an absolute error of $17-48 \%$, and the highest error occurs at $406 \%$ for the smallest flood $(\mathrm{TL}=496 \mathrm{GL})$. AET time-series of 8-day ET volume reveals that CMRSET estimates a higher than expected minimum of $85 \mathrm{GL} / 8$-day for the floodplain during prolonged droughts but reproduces dynamics that well correlate with variation in the inundation area and responds to both water and vegetation land cover variations. MOD16 underestimates AET for all the floods, only accounting for $17-37 \%$ of total loss and it is does not correlated well with the inundation extent. Pixel based comparison of MOD16 time series also shows very low ET values for peak vegetation in this arid region. For CMRSET, it is expected that a lower limit for minimum AET from non-inundated pixels could improve water balance estimates for medium sized floods but will have a lesser effect for small floods. The error in the latter case will also be due to the limitation of MODIS spatial resolution in properly capturing land cover changes (i.e. inundation extents and vegetation responses). Misclassification of land cover and the dependency of the MOD16 model on estimating water cover fraction based on relative humidity are suggested to be the main sources of error for this product.
\end{abstract}

Keywords: MOD16, CMRSET, evapotranspiration, arid regions, Cooper Creek 
Mohammadi et al., Evaluation of remotely sensed evapotranspiration products in Australian arid regions, case study: Cooper Creek, Queensland

\section{INTRODUCTION}

Evapotranspiration (ET) is the second largest term after precipitation in the global terrestrial water budget and it is equivalent to $90 \%$ or more of the annual precipitation in the arid and semi-arid regions (Huxman et al., 2004). Therefore, uncertainty of ET fluxes comprises one of the major components of uncertainty in the water balance of arid region catchments. These regions are often sparsely populated with poor gauging infrastructure but contain high value ecosystems and agricultural areas dependent on limited water resources.

Remote sensing is the most feasible tool to provide actual ET information over large-scale landscapes. Currently, there are multiple ET products over Australia utilizing MODerate resolution Imaging Spectroradiometer (MODIS) reflectance data, together with ground meteorological measurements. The 8-day composite MODIS Global Terrestrial Evapotranspiration Product (NASA MOD16A2), herein called MOD16-AET, provides global coverage to estimate ET fluxes, accounting for plant transpiration, rainfall interception from wet canopy surfaces, potential evaporation from saturated wet surfaces and discriminates between the evaporation rate of moist and wet soils (Mu et al., 2011). Guerschman et al. (2009) developed another ET product using MODIS data, called the CSIRO MODIS Reflectance Scaling Actual ET (CMRSET-AET) for Australia with the same temporal, but finer spatial resolution than the NASA's ET product (MOD16). MOD16 data were evaluated by 46 eddy covariance towers across North and South America with nine typical land cover types, including forests, shrublands, savannahs, grassland and croplands, but with more emphasis in calibration of temperate to wet climates zones (Mu et al., 2011). The CMRSET-AET data were calibrated by seven flux towers across Australia (six vegetated sites with seasonally flooded wetlands and one open water site) and its performance was evaluated in 227 unregulated catchments, none of which is located in the arid and semi-arid regions of inland Australia. Hence, further validation of these datasets in broader climate types, such as arid zone catchments of inland Australia, is necessary to assess their potential in hydrological studies.

In order to examine the performance of mentioned ET products in arid regions, a large reach of Cooper Creek in the Lake Eyre Basin (LEB) was chosen. The aim of this paper is to test spatial and temporal behaviour of remotely sensed AET products at a reach scale by utilizing water losses estimated by water balance analysis of individual flood events. It is expected that having more accurate satellite-based AET estimates will be helpful in constraining uncertain terms, such as ungauged run-off. Also, the spatial distribution of losses would greatly assist in the development and calibration of a distributed hydrological modelling approach.

\section{CASE STUDY}

The study area covers Cooper Creek in Queensland between the upstream confluence of Thomson and Barcoo Rivers to Cullyamurra gauging station where the river enters South Australia (Figure 1). The reach comprises a large floodplain with an area of $22,000 \mathrm{~km}^{2}$ and length of $480 \mathrm{~km}$. Based on the Shuttle Radar Topographic Mission (SRTM) digital elevation model (DEM) data (Dowling et al., 2011), Cooper Creek floodplain is very flat with an average slope of $1.7 \times 10^{-4}$, encompassing a complex network of anastomosing channels. Cooper Creek's inflow is seasonal with high inter-annual variability. Large floods originating from Thompson and Barcoo Rivers are associated with monsoon rainfall on the western slopes of Great Dividing Range in Queensland. Mean annual combined streamflow from these tributaries is 3150 GL with a coefficient of variation of 1.35; whereas maximum inflow since 1966 is 23,500 GL (McMahon et al., 2008b). Direct rainfall on the floodplain is also highly variable. Based on data provided by Australian Water Availability Project (AWAP, Jones et al., 2009), the average rainfall over the floodplain is $250 \mathrm{~mm}$ with a coefficient of variation of 0.72 for the period of 2000-2012. Maximum rainfall occurs in the upstream part of the reach, with an annual average of $300 \mathrm{~mm}$, and decreases toward the southwest to $200 \mathrm{~mm}$ (McMahon et al., 2008a). Reach-scale transmission losses, the proportion of inflow trapped in the reach and mainly lost through evapotranspiration and groundwater recharge, are very high, comprising more than 75\% of gauged inflow in the small and medium floods and decreasing to $60 \%$ for large events (Knighton and Nanson, 1994). However, the contribution to the floodplain from direct rainfall and runoff from ungauged, in-reach subcatchments has not been investigated in the water balance of the Cooper Creek. Moreover, these processes have been ignored in the previous water balance investigations done using a 'black box' approach at the reach scale (e.g. Knighton and Nanson, 1994). Three main processes were identified by Knighton and Nanson (1994) for the internal water losses: evapotranspiration, percolation to the groundwater and terminal storage of water in surface depressions, such as lakes and water holes. 
Mohammadi et al., Evaluation of remotely sensed evapotranspiration products in Australian arid regions, case study: Cooper Creek, Queensland

\section{MATERIALS AND METHODS}

Daily upstream flow data for Thompson and Barcoo Rivers were provided by the Department of Natural Resources and Mines in Queensland (https://www.dnrm.qld.gov.au /water/water-monitoring-and-data/portal) for Stonehenge and Retreat stations (Station No. 003203A and 003301B, respectively) for the period of 2000-2012. Downstream flow data for Cullyamurra Station (Station No. A0030501) were obtained from WaterConnect, South Australia's water information portal, (https://www.waterconnect.sa.gov.au/Systems/ $\underline{\text { RTWD/SitePages/Home.aspx }}$ ) and daily raster rainfall data with $0.05^{\circ}$ spatial resolution for the same period was derived from AWAP (Jones et al., 2009).
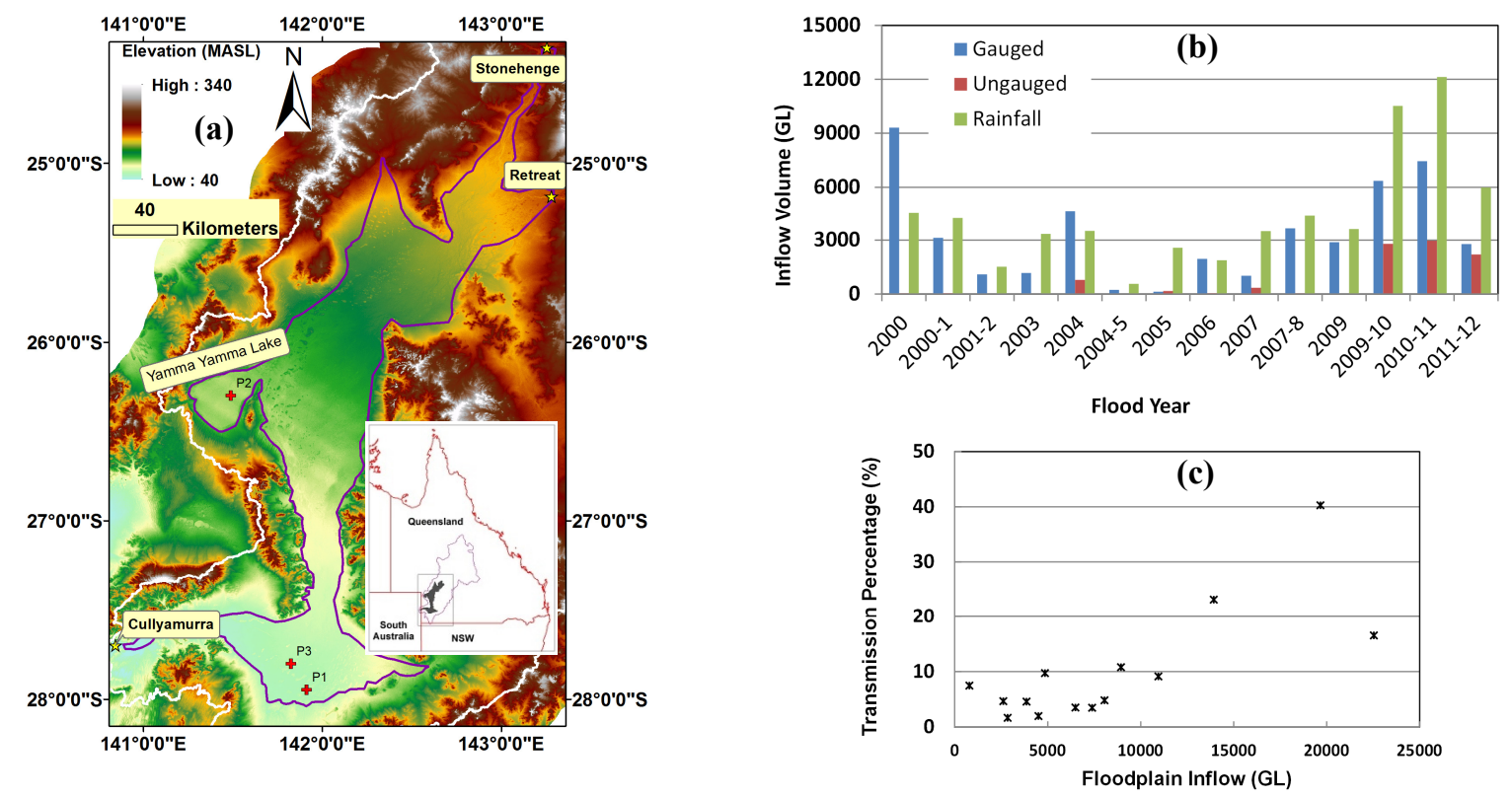

Figure 1. (a) Cooper Creek and its catchment in Australia, SRTM DEM, and position of upstream (Stonehenge and Retreat) and downstream (Cullyamurra) gauging stations. Also shown are three sample points in the floodplain (P1-3), catchment border (white line) and floodplain border (purple line); (b) Volumes for gauged streamflow, ungauged streamflow and direct rainfall on study reach for 14 floods between 2000 and 2012; (c) Relation between bulk floodplain water input (inflow volume through gauged, ungauged streams and rainfall), and transmission percentage (percentage of outflow in Cullyamurra Station to the inflow) for the floods.

Remotely sensed actual evapotranspiration data were acquired from two sources: CMRSET-AET provides AET for the period of 2000-2013 with 8-day temporal and 250-m spatial resolution. The data are available at http://remote-sensing.nci.org.au/u39/public/data/wirada/cmrset. Also, MOD16-AET was downloaded from the Numerical Terradynamic Simulation Group (NSTG) webpage in the University of Montana (www.ntsg.umt.edu/project/mod16). It has 8-day temporal resolution, but the spatial resolution is $1 \mathrm{~km}$. Also, for detecting land cover changes the following indices were used for the daily Terra MODIS reflectance products (MOD09GA) with spatial resolution of $500 \mathrm{~m}$ :

$$
\mathrm{NDVI}=\frac{\mathrm{NIR}-\mathrm{R}}{\mathrm{NIR}+\mathrm{R}} \quad \text { (1) } \quad \operatorname{mNDWI}=\frac{\mathrm{G}-\mathrm{SWIR} 1}{\mathrm{G}+\text { SWIR1 }} \quad \text { (2) } \quad \text { LSWI }=\frac{\mathrm{NIR}-\mathrm{SWIR} 1}{\mathrm{NIR}+\text { SWIR1 }}
$$

G, R, NIR and SWIR1 denote reflectance values of green (band 3), red (band 1), near infrared (band 2) and shortwave infrared (band 6) of MODIS, respectively. NDVI is used for tracking vegetation changes and the modified normalized difference water index (mNDWI, Xu, 2006) is used to discriminate water bodies from soil and vegetation. Land surface water index (LSWI; Xiao et al. 2005) is sensitive to the moisture in the form of wet soil, water and vegetation and it is used here for differentiating dry soil from inundated regions. Daily MODIS data were downloaded from NASA Land Processes Distributed Active Archive Centre website (http://reverb.echo.nasa.gov). Remotely sensed ET products and MODIS reflectance were all reprojected to the WGS84 geographic coordinate and the information from the study area were extracted for analysis.

For better estimation of inflows to the Cooper Creek floodplain, volume of water from ungauged catchments between upstream and downstream gauging stations was calculated. Ungauged inflows were estimated by a 
Mohammadi et al., Evaluation of remotely sensed evapotranspiration products in Australian arid regions, case study: Cooper Creek, Queensland

conceptual rainfall run-off model called the probability distributed model (PDM, Moore, 2007). Monthly potential evaporation data prepared by Bureau of Meteorology (http:/www.bom. gov.au/climate/data) and AWAP rainfall data were used as input. The model was calibrated using 13 years of the gauged Darr River sub-catchment of Cooper Creek between 2000 and 2012, the closest gauged sub-catchment, located $150 \mathrm{~km}$ upstream of Stonehenge Station. The calibrated parameters were then applied to run PDM for the ungauged catchments and to calculate ungauged surface runoff flowing to the study reach. In the absence of any other gauged discharge data close to the study reach, it is assumed that rainfall-runoff in the ungauged catchments behaves in a similar manner to the calibration catchment. We note that the ungauged catchments have similar climate and morphology to the gauged Darr River sub-catchment.

In order to estimate water balance elements of each flood event, the AWAP rainfall, CMRSET-AET and MOD16-AET for the Cooper Creek floodplain were extracted from a few days antecedent to each event to a few days prior to the following event. Inflows to the floodplain, including upstream discharge and rainfall, mainly enter the floodplain during the flow events, but for estimating remotely sensed ET volumes, the period considered for each flood event was extended to a few days before the next flood.

\section{RESULTS}

\subsection{Water Balance of the Cooper Creek}

In Table 1, the main elements of the Cooper Creek water balance, including rainfall and ungauged streamflow volume, are compared to the satellite-derived AET products. The range of gauged upstream flow for the floods between 2000 and 2012 is wide, from 119 to 9319 GL. In Figure 1b the volume of gauged and ungauged inflow and rainfall volume are compared. Ungauged flow is significant for the large floods, especially between 2010 and 2012, bringing more than $2000 \mathrm{GL}$ of water to the reach, while the in-reach rainfall volume is quite comparable to gauged inflow and in most of the events it is higher than it (except floods in 2000, 2004 and 2006).

Table 1. Cooper Creek Floods between 2000 and 2012, estimated and measured surface runoff, rainfall height and volume and AET volume and corresponding errors of MOD16 and CMRSET products.

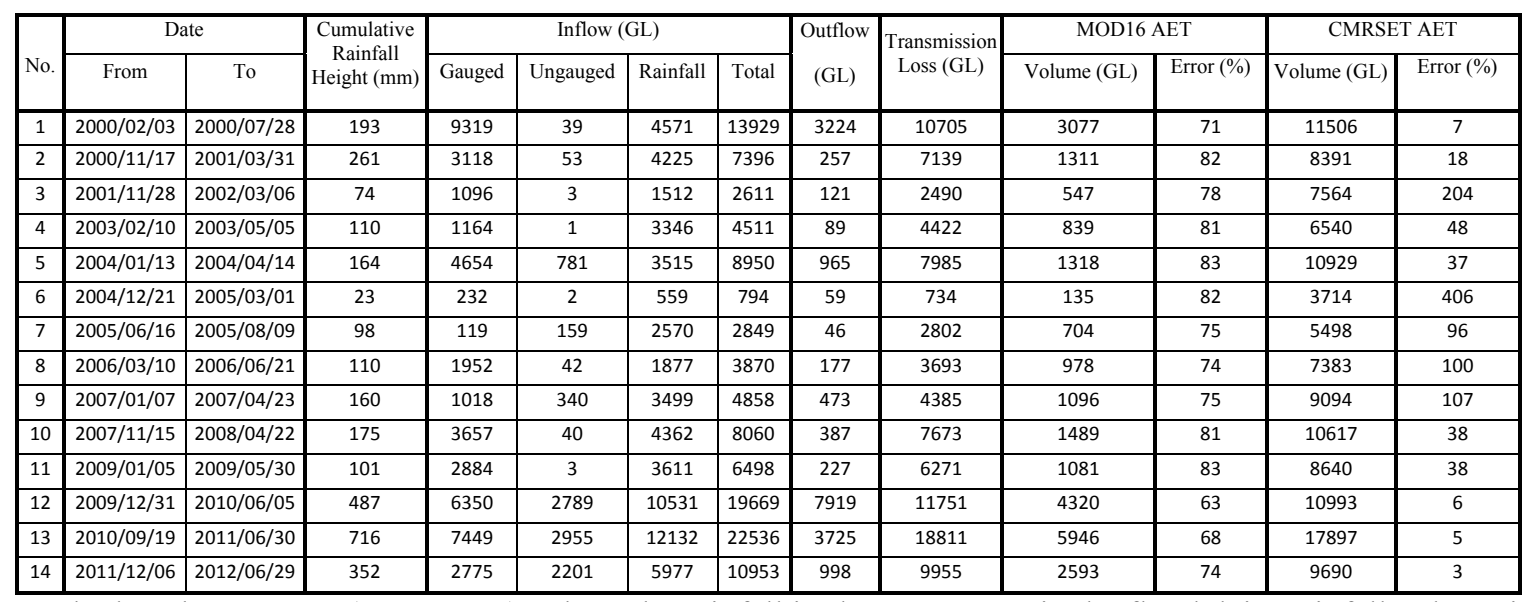

For the last three events (2010-2012), where the rainfall is above $350 \mathrm{~mm}$ in the floodplain, rainfall volume is between $60 \%$ and $115 \%$ greater than the gauged surface run-off. Although, the rainfall height is low in dry and moderate years, the volume of water is considerable due to the large area of the floodplain. While the rainfall in many of the events may not contribute significantly to runoff in this landscape, it does need to be accounted for when comparing to AET estimates. In summary, considering the effect of rainfall and ungauged runoff, especially in wet years, is vital in the water balance.

Loss of water in the study reach is very high, ranging $60-98 \%$ of the sum of all inflow terms. In Figure $1 \mathrm{c}$ the transmission percentage (the percentage of outflow at Cullyamurra station to the inflow from gauged and ungauged catchments and rainfall volume) is illustrated. For the floods with less than 11,000 GL inflow, the maximum amount of outflow is around $10 \%$ of the inflow. Transmission percentage increases with the increase of volume above this level to a maximum of $40 \%$ for the $2009-2010$ floods. Maps of cumulative rainfall height for the large events (e.g. in 2000 and 2010), not presented in this paper, show that the spatial pattern of rainfall and the proximity of rainfall mass occur close to the downstream outlet of Cooper Creek and this spatial distribution of rainfall is likely to play an important role in the variation of transmission ratio 
Mohammadi et al., Evaluation of remotely sensed evapotranspiration products in Australian arid regions, case study: Cooper Creek, Queensland

for the reach. Finally, uncertainties need to be acknowledged in the water balance estimate. Uncertainties in rainfall can be the major source of error; however, RMSE for daily AWAP rainfall data is limited to $3.8 \%$ (Jones et al., 2009) and this range of error cannot make a significant effect on the loss term. For the ungauged inflow estimates, errors related to model uncertainty will be higher, but this term will be most significant in large floods (2010-2012) and less so for the smaller size floods.

\subsection{Remotely Sensed ET}

AET results for the Cooper Creek floods are compared against floodplain transmission losses in Table 1 and illustrated in Figure 2. For the four major floods of 2000 and 2009-2012, with more than 9,500 GL of transmission losses, CMRSET estimates of AET match overall transmission losses with less than $8 \%$ absolute error. For the smaller floods, CMRSET-AET apparently overestimates transmission losses and the error increases when the size of floods decreases. In the floods with 4,000-8,000 GL transmission losses, the difference between remotely sensed AET and transmission losses varies between $17 \%$ and $48 \%$; while this figure increases to over $96 \%$ in floods with less than $4,400 \mathrm{GL}$, and peaks to more than $400 \%$ for the smallest flood with a transmission loss of 405 GL. On the other hand, MOD16-AET significantly underestimates loss in the study reach. The range of MOD16-AET is between 135 and 5,946 GL while the range of transmission loss fluctuates between 734 and 18,881 GL; so, MOD16-AET accounts for only 17-37\% of water loss.

In order to have a better insight to the AET dynamics, time series of 8-day AET are compared to inundation area (Figure $2 b$ ). Time series of inundation area were calculated by the total area of the daily Terra MODIS image pixels satisfying LSWI $>0$. CMRSET time series yields a minimum of $85 \mathrm{GL}$ for 8-day loss volume during the given period. This indicates a minimum daily AET of $0.5 \mathrm{~mm}$ over the floodplain and given the aridity of the region, this may indicate overestimation of background AET. In Figure $2 b$, the minimum areas of inundation were less than $500 \mathrm{~km}^{2}$ in low flow years, such as 2002 and 2005 . Therefore, it is expected that spatially averaged AET over the floodplain is markedly less than $85 \mathrm{GL} / 8$-day during long periods without flow. One of the possible reasons for better estimates of CMRSET AET matching the transmission losses of the large floods is their shorter intervals to the next flood. For the four large events, this mean interval is 128 days and the absolute error for these floods is below $8 \%$, while for the 2004 flood event, with inflow close to the large floods (7985 GL) but a longer after-flood interval (251 days), the CMRSET estimate is 37\% more than the estimated water balance loss. The CMRSET data respond coincidentally to the inundation area peaks in the medium and large events (Figure 2b); however, it overestimates TL for the small floods (e.g. floods between 2001 and 2003).
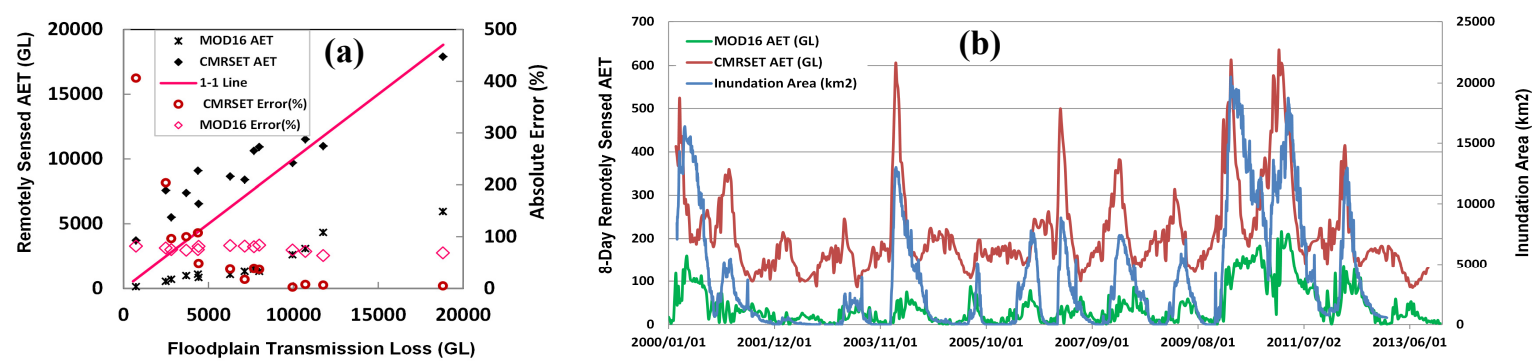

Figure 2. (a)Transmission loss in the Cooper Creek versus MOD16 and CMRSET actual evapotranspiration products for 14 floods in the period of 2000 to 2012; (b) Time-series of 8-day evapotranspiration volume in the Cooper Creek estimated by MOD16 and CMRSET for the period of 2000 to 2013 and daily inundation area estimated by daily Terra MODIS products with LSWI $>0$.

According to Figure 2b, MOD16 time series shows zero AET in many occasions over the study period, which is likely to underestimate AET. The MOD16 data fail to follow the peaks of the inundation area timeseries, which represents the mapped overall availability of water in the floodplain. For example, during 2003 to 2008 , floodplain loss varies between 734 to 7985 GL (Table 1) and in Figure 2b, the inundation area magnitudes for these floods are proportional to the volume of inflow. However, the MOD16 AET time series show almost the same responses for the floods in this period. The main increase in its 8-day AET occurred for the four biggest floods with more than $9955 \mathrm{GL}$ of transmission loss but even in these events, MOD16 fluxes underestimate the water balance floodplain loss with $69 \%$ error.

In order to see responses of MOD16 and CMRSET to water and vegetation cover dynamics, three sample points (Figure 1) were selected showing the NDVI and mNDWI responses to different behaviours in land cover. These were analysed over an interval from a few days before the commencement of the 2004 flood, 
when the floodplain is almost dry due to long period of no flow, to a few days before the commencement of the next flood in late December 2004. Point P1 experienced a bare soil cover before flooding, water coverage during flooding and a subsequent flood vegetation response, which gradually attenuates to bare soil postflooding due to prolonged water stress (Figure 3a). Point P2 is located in Lake Yamma Yamma and changes from bare soil to a strong water response due to the filling of the lake and insignificant subsequent vegetation response (NDVI) (Figure 3b). Point P3 is representative of regions in the floodplain which are not flooded, due to having a higher elevation to the surrounding areas, and does not show significant vegetation or water response at the $500 \mathrm{~m}$ pixel resolution (Figure 3c).
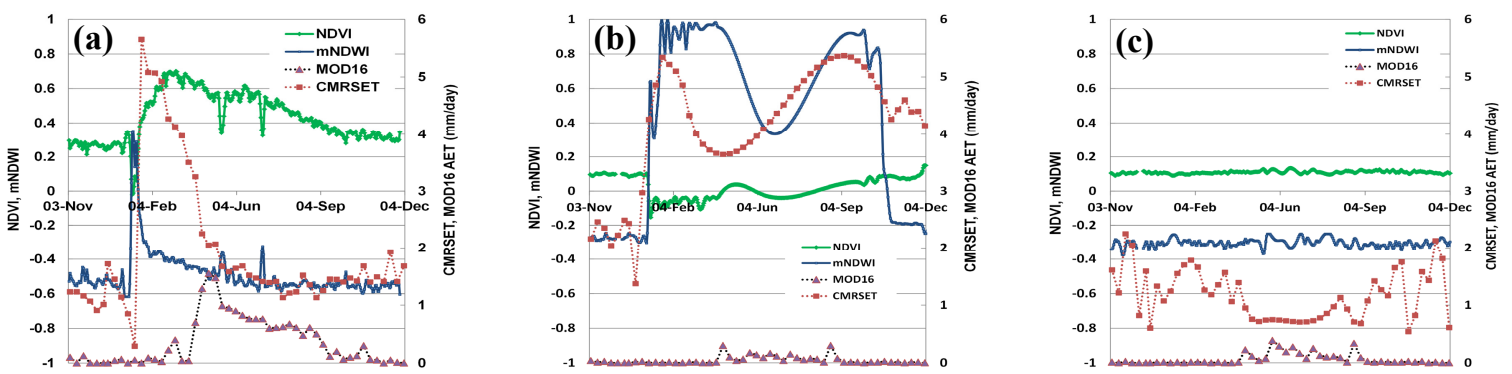

Figure 3. Time series of NDVI, mNDWI and AET for three points (see Figure 1 for locations) in the Cooper Creek from two months before the 2004 flood event to a few days before the commencement of 2005 event; (a) Point P1 represents a sequence of bare soil-water-vegetation on the floodplain; (b) Point P2 represents a bare soil - water sequence in Lake Yamma Yamma without a vegetation response; (c) Point P3 shows a typical point in the floodplain which is not inundated.

CMRSET gives an average of $1.2 \mathrm{~mm} /$ day of AET before the flood at P1 and a peak of AET at $5.65 \mathrm{~mm} / \mathrm{day}$ coinciding with pixel inundation (mNDWI) and subsequent vegetation growth (NDVI). The peak daily AET is close to the long-term average daily areal potential evapotranspiration (APET) of the region in February $(5.34 \mathrm{~mm} /$ day) produced by the Bureau of Meteorology (BOM) (Chiew et al., 2002). The daily AET rate then decreases to $1.45 \mathrm{~mm}$ /day as the vegetation decreases. Figure $3 \mathrm{~b}$ shows $2.3 \mathrm{~mm}$ /day for pre-flood AET at P2 located in the dry lake bed but with a probable shallow groundwater table. The CMRSET AET increases to $5.4 \mathrm{~mm} /$ day, conforming well to the BOM APET of $5.34 \mathrm{~mm} /$ day mentioned above, at P2 during inundation, however, the AET time series has a time lag with mNDWI time series. In contrast, MOD16 AET does not respond to inundation at $\mathrm{P} 1$ and $\mathrm{P} 2$ and maintains low AET rates during these flooded periods. The slight increase of MOD16-AET to $1.5 \mathrm{~mm} /$ day at $\mathrm{P} 1$ is mainly attributed to the increase of NDVI. These observations indicate that MOD16 is failing to capture evaporation from open water and its sole sensitivity is to the vegetation in this arid region. Finally, CMRSET-AET for non-flooded points (P3) shows a large variation between 0.6 and $2.1 \mathrm{~mm}$ /day despite the stability of the NDVI and mNDWI signal. Cumulative rainfall height over the same period for P3 is $125.3 \mathrm{~mm}$, whereas the figures for CMRSET and MOD16 AET is 478 and $26 \mathrm{~mm}$, which indicates overestimation by CMRSET and underestimation by MOD16 products. This result is consistent for many non-flooded points not mentioned here and suggests the calculated CMRSET AET for the non-flooded pixels may be overestimated and requires adjustments.

\section{DISCUSSION AND CONCLUSION}

In this paper, AET products of MOD16 and CMRSET were evaluated over a large-scale, arid floodplain of Cooper Creek. Results indicate that MOD16 greatly underestimates evapotranspiration losses for the all flood ranges, equivalent to only $17 \%$ to $37 \%$ of the total losses. In addition, investigation of the MOD16-AET time series for representative sample points shows that this product does not capture AET during inundation times. Evaluation of the MOD16 ET product by Kim et al. (2012) over 17 sites in Asia showed good estimation of ET by MOD16 for forests but underestimated ET in rice paddy croplands. Significant underestimation of MOD16-AET in irrigated croplands of China (Tang et al., 2015) and arid regions of Africa in wet seasons (Trambauer et al., 2014) supports the shortcomings of MOD16 in estimating open water evaporation of arid floodplains. Those studies did not compare AET time-series of pixels with water and vegetation dynamics, as explicitly as shown here, but identified land cover misclassification by the annual MOD12Q1 product (used in the MOD16 model) as a source of error. This issue seems to be applicable for Cooper Creek, where rapid land cover changes occur in a few months during flooding periods. Another probable reason for this issue in Cooper Creek can be related to the identification process of water cover fraction (Mu et al., 2011). Water cover fraction for a soil is constrained to zero when relative humidity $(\mathrm{RH})$ of air is less than $70 \%$ and for 
Mohammadi et al., Evaluation of remotely sensed evapotranspiration products in Australian arid regions, case study: Cooper Creek, Queensland

$\mathrm{RH}>70 \%$ water fraction was estimated as the forth power of relative humidity $(\mathrm{RH})^{4}$. For the arid regions with high moisture deficit and summer flooding, lower air humidity is expected and this confounds the MOD16 estimation of water cover fraction.

CMRSET performs well in the four largest flood events of Cooper Creek during 2000 - 2012 with less than $8 \%$ error; but it potentially overestimates losses for the floods with less than $8000 \mathrm{GL}$ transmission loss. The error grows exponentially and reaches $400 \%$ for the smallest event. Investigation of the CMRSET time series of 8-day AET for representative sample pixels in the floodplain indicates that the minimum evapotranspiration does not approach zero even in extended dry periods. This may be an overestimation but further work is required to investigate it. One of the possible reasons for overestimating AET in smaller flood events is the spatial resolution of data used for modelling. The best resolution of MODIS products for all seven visible, near infrared and shortwave infrared is $500 \mathrm{~m}$. Small floods of Cooper Creek mainly flow in the primary channels which have widths of a few tens of meters (Knighton and Nanson, 1994) and the signals of water or vegetation for the narrow waterways cannot be captured by MODIS with 500-m resolution. Consequently, even after recalibration of the CMRSET model in the arid regions, promising AET results would be not be expected for low volume floods and better estimations are subject to the utilization of future generations of remotely sensed data with higher spatial resolution. Compared to MOD16, the time series of CMRSET-AET can successfully keep track of expected AET dynamics related to observed water and vegetation responses in pixels and the peaks in ET volume corresponds well to the inundation area dynamics.

\section{REFERENCES}

Chiew, F., Wang, Q.J., McConachy, F., James, R., Wright, W., deHoedt, G. (2002). Evapotranspiration Maps for Australia [online]. In: Water Challenge: Balancing the Risks: Hydrology and Water Resources Symposium 2002. Barton, A.C.T.: Institution of Engineers, Australia, 167- 177

Dowling, T. I., Brooks, M., \& Read, A. M. (2011, October). Continental hydrologic assessment using the 1 second (30m) resolution Shuttle Radar Topographic Mission DEM of Australia. In MSSANZ 2011 Perth.

Guerschman, J. P., Van Dijk, A. I., Mattersdorf, G., Beringer, J., Hutley, L. B., Leuning, R., ... \& Sherman, B. S. (2009). Scaling of potential evapotranspiration with MODIS data reproduces flux observations and catchment water balance observations across Australia. Journal of Hydrology, 369(1), 107-119.

Huxman, T. E., Smith, M. D., Fay, P. A., Knapp, A. K., Shaw, M. R., Loik, M. E., ... \& Williams, D. G. (2004). Convergence across biomes to a common rain-use efficiency. Nature, 429(6992), 651-654.

Jones, D. A., Wang, W., \& Fawcett, R. (2009). High-quality spatial climate data-sets for Australia. Australian Meteorological and Oceanographic Journal, 58(4), 233.

Kim, H. W., Hwang, K., Mu, Q., Lee, S. O., \& Choi, M. (2012). Validation of MODIS 16 global terrestrial evapotranspiration products in various climates and land cover types in Asia. KSCE Journal of Civil Engineering, 16(2), 229-238.

Knighton, A. D., \& Nanson, G. C. (1994). Flow transmission along an arid zone anastomosing river, Cooper Creek, Australia. Hydrological Processes, 8(2), 137-154.

McMahon, T. A., Murphy, R. E., Peel, M. C., ... (2008a). Understanding the surface hydrology of the Lake Eyre Basin: part 1-rainfall. Journal of arid environments, 72(10), 1853-1868.

McMahon, T. A., Murphy, R. E., Peel, M. C., Costelloe, J. F., \& Chiew, F. H. (2008b). Understanding the surface hydrology of the Lake Eyre Basin: part 2-streamflow. Journal of Arid Environments, 72(10), 1869-1886.

Moore, R. J. (2007). The PDM rainfall-runoff model. Hydrology and Earth System Sciences Discussions, 11(1), 483-499.

Mu, Q., Zhao, M., \& Running, S. W. (2011). Improvements to a MODIS global terrestrial evapotranspiration algorithm. Remote Sensing of Environment,115(8), 1781-1800.

Tang, R., Shao, K., Li, Z. L. (2015). Multiscale Validation of the 8-day MOD16 Evapotranspiration Product Using Flux Data Collected in China. IEEE JOURNAL OF SELECTED TOPICS IN APPLIED EARTH OBSERVATIONS AND REMOTE SENSING, 8(4), 1478-1486.

Trambauer, P., Dutra, E., Maskey, S., Werner, M., Pappenberger, F., Van Beek, L. P. H., \& Uhlenbrook, S. (2014). Comparison of different evaporation estimates over the African continent. Hydrology and Earth System Sciences, 18 (1), 2014.

Xiao, X., Boles, S., Liu, J., Zhuang, D., Frolking, S., Li, C., ... \& Moore, B. (2005). Mapping paddy rice agriculture in southern China using multi-temporal MODIS images. Remote Sensing of Environment, 95(4), 480-492.

$\mathrm{Xu}, \mathrm{H}$. (2006). Modification of normalised difference water index (NDWI) to enhance open water features in remotely sensed imagery. International Journal of Remote Sensing, 27(14), 3025-3033. 